\title{
КАЧЕСТВО ЖИЗНИ ТРУДОВЫХ МИГРАНТОВ ИЗ УКРАИНЫ: КОНЦЕПТУАЛЬНЫЕ ВОПРОСЫ И РЕАЛЬНЫЕ ПРОЦЕССЫ
}

\author{
Ирина МАЙДАНИК ${ }^{\odot}$, к.соц.н., старший научный сотрудник, \\ Институт демографии и социальных исследований имени М.В. Птухи, \\ Национальная академия наук Украины \\ DOI: https://doi.org/10.36004/nier.cdr.2019.14-09 \\ JEL Classification: I31, J31, J61, J81.
}

Статья посвящена исследованию теоретических и прикладных вопросов качества жизни трудовых мигрантов. Установлено, что основныли альтернативными методами для оценки благосостояния населения являются разработка интегрального индекса или выбор набора пригодных для этой иели показателей. Анализ литературы свидетельствует о том, что изучение качества жизни мигрантов в существующих источниках основывается на разных подходах в зависимости от логической целесообразности.

Для исследования качества жизни украинских трудовых мигрантов за рубежом в статье используются эмпирические данные, полученные в ходе трех раундов Всеукраинского обследования трудовой мигращии (ОТМ), проведенных в 2008 г., 2012 г. и 2017 г. Государственной службой статистики Украинь и партнерами. Дополнительным источником данных служат результаты выборочного исследования ТЕМПЕР, проведенного в декабре 2017-мае 2018 гг. среди украинцев из западных областей, работавших в Италии и Польше в период 1996-2017г2.; в качестве референтной группь опрос также охватил лии, не имеющих миграционного опыта. Установлено, что основные характеристики занятости мигрантов не соответствуют законодательным трудовым нормативам, что негативно влияет на качество жизни исследуемой группы. Однако более высокий уровень зарплат за рубежом может салаживать влияние негативных характеристик занятости.

Ключевые слова: качество жизни, показатели качества жизни, благосостояние, миграџия, трудовая миграџия, возвратная миграџия.

The article is devoted to the theoretical and applied issues of the labor migrants' quality of life investigation. It has been reviled that the main alternative methods for assessing the population wellbeing currently are the development of an integral index or the selection of a set of indicators suitable for this purpose. Literature analysis indicates that migrants' quality of life studies in existing sources are based on different approaches, depending on reasonability.

To investigate the quality of life of Ukrainian labor migrants abroad, the empirical data obtained during three rounds of the All-Ukrainian Labor Migration Survey (LMS) conducted in 2008, 2012, and 2017 by the State Statistics Service of Ukraine and partners are used in the article. An additional source of information is the results of the sample study TEMPER carried out in December 2017 - May 2018 among Ukrainians from the western regions of the country who worked in Italy and Poland in 1996-2017; as a reference group, the survey also covered people who did not have migration experience. It has been reviled that the main characteristics of migrant employment do not comply with legislative labor standards, which negatively affects the quality of life of this group. However, higher salaries abroad are able to mitigate the effects of negative employment characteristics.

Key words: quality of life, quality of life indicators, wellbeing, migration, labor migration, return migration.

\footnotetext{
${ }^{\circledR}$ Ирина Майданик, $\underline{\text { Sulamif@online.ua }}$
} 
В основе современных научно-практических разработок в области гуманитарного знания лежит убеждение международного сообщества экспертов в том, что качество жизни населения является одной из основных характеристик уровня развития государства. Оценивание качества жизни выступает ключевым вызовом при мониторинге прогресса на пути к достижению Целей развития тысячелетия, принятых на саммите ООН в сентябре 2000 г. [8, с. 3]. Соотношение качества жизни населения и миграционных процессов пересекается в двух плоскостях: во-первых, основные характеристики миграций в определенной местности служат индикатором, демонстрирующим разницу между уровнем развития стран (регионов) происхождения и прибытия мигрантов (например, масштабный выезд населения, в особенности высококвалифицированного, за рубеж, свидетельствует о более высоком уровне жизни в странах прибытия). Вторым аспектом взаимосвязей между указанными категориями выступает изучение качества жизни самих мигрантов, поскольку они значительно отличаются от всего населения по обширному перечню показателей.

Исследовательский фокус в рамках данной статьи направлен на изучение последней позиции. Выбирая мигрантов в качестве объекта исследования, следует учитывать большую неоднородность этой группы, а также региональную специфику, поскольку локальный контекст во многом определяет природу миграционных процессов. Эта публикация ограничивается изучением трудовых мигрантов из Украины, однако, материалы и рассуждения, представленные здесь, могут оказаться полезными и для ученых, исследующих миграции населения из других стран и регионов.

Bсе многообразие литературы, посвященной тематике оценки качества жизни, сводится к разработке двух основных подходов: использованию интегрального индекса либо набора показателей для измерений в этой сфере. Для иллюстрации первой позиции можно использовать индекс человеческого развития [11], впервые представленный в 1990 г. в докладе Программы развития ООН (ПРООН), в качестве альтернативного инструмента оценивания прогресса на государственном уровне. В более позднюю научную дискуссию вплетается идея использования показателей субъективной самооценки уровня и качества жизни населения. Так, в 2006 г. впервые был рассчитан Международный индекс счастья [5], основывающийся на трех показателях: субъективной удовлетворенности людей жизнью, ожидаемой продолжительности жизни и так называемом «экологическом следе» (т.е. мере воздействия человека на среду его обитания).

Среди важных международных разработок, использующих для оценивания качества жизни набор показателей, следует упомянуть индекс качества жизни, разработанный аналитическим отделом журнала «Экономист» в 2005г. [10]. В этой работе эксперты выделили девять областей благополучия населения: материальное благополучие, здоровье, политическая стабильность и безопасность, семейная жизнь, общественная жизнь, климат и географическое расположение, гарантии занятости, политическая свобода и гендерное равенство. Европейская статистическая группа содействия по измерению прогресса [4] при исследовании качества жизни выделили схожие по характеру, но не идентичные области: материальные жилищные условия, продуктивная или иная основная деятельность, здоровье, образование, досуг и социальное взаимодействие, экономическая и физическая безопасность, управление и основные права, естественная и жизненная середа, общий жизненный опыт.

Рассмотрение научных вопросов, касающихся качества жизни мигрантов, происходит в результате включения этой категории населения в процесс изучения общего благосостояния либо в виде отдельных исследований, направленных исключительно на эту целевую группу. Так, в 2017 Организация Экономического Сотрудничества и Развития провела исследование на анализируемую тематику под названием: «Как жизнь? 2017: Измерение благосостояния» [9]. В ходе этой аналитической инициативы эксперты уделили внимание оцениванию качества жизни миграционных контингентов, отмечая повышенную сложность получения исходных данных об этой группе. 
Исследования международного индекса счастья, упоминаемого ранее, дают богатый материал, иллюстрирующий влияние изменения места жительства на качество жизни [7]. Международные мигранты оценивают качество своей жизни после переезда в другую страну в среднем на 9 процентов выше, чем до выезда. Впрочем, эти результаты поддаются региональному влиянию: наибольший «прирост счастья», вполне прогнозируемо, наблюдается при переезде из развивающихся регионов в развитые страны. В этой закономерности наблюдается одно заметное исключение - мигранты из Латинской Америки и Карибского региона не становятся заметно счастливее после переезда в Северную Америку, Австралию или Новую Зеландию. Вероятно, это происходит из-за избыточной важности социальной жизни для латиноамериканцев, которую они теряют в результате переезда. В соответствии со Всемирным докладом о счастье, в среднем через пять лет после переезда, уровень счастья мигрантов и местного населения выравнивается: происходит так называемая ассимиляция счастья. Эксперты объясняют постепенное снижение уровня счастья после прибытия мигрантов в новую страну изменением референтной группы для сравнения: они перестают соотносить свои условия жизни с существующими на родине и начинают ориентироваться на стандарты, распространенные в принимающей стране.

Литература, направленная на изучение качества жизни мигрантов как отдельной группы населения, часто имеет теоретический характер из-за отсутствия достаточной эмпирической базы в этой области. Миграционная статистика является одной из самых несовершенных отраслей этой науки, в результате чего исследователи вынуждены ориентироваться на результаты разрозненных выборочных исследований в этой сфере. Поэтому миграционные данные часто бывают несистемными и несопоставимыми. Среди аналитических разработок в этой области полезно обратить внимание на труд «Благополучие мигрантов-детей и молодежи», написанный зарубежными учеными К. Хартген (Kenneth Hartgen) и С. Класен (Stephan Klasen) [6]. Эти эксперты в своей работе рассматривают понятие благополучия как синоним качества жизни и выделяют шесть основных факторов его оценки: занятость/безработица; образование; уровень жизни; здоровье; социальная сплоченность; безопасность и преступность. К сожалению, из-за отсутствия достаточной эмпирической базы, на последующих страницах этой статьи всесторонне рассмотреть все перечисленные области, относительно украинских трудовых мигрантов, не представляется возможным. Последующий анализ будет основываться на имеющейся эмпирической базе.

Выдающиеся эксперты в области изучения качества жизни М. МакГилливрей и М. Кларк [8, с. 4] высказывают удивление, что, несмотря на существенную эволюцию в мировой науке относительно концепции благополучия, основным его показателем во многих исследованиях все еще остается доход. Особенно справедливо это высказывание касается трудовых мигрантов, учитывая, в основном, экономическую мотивацию переезда за рубеж этой категории населения. Для оценивания материального благополучия трудовых мигрантов, равно как и других аспектов качества их жизни, в рамках этой статьи мы будем использовать данные трех раундов Всеукраинского обследования трудовой миграции (ОТМ), проведенных в 2008 г. [3], 2012 г. [1] и 2017 г. [2], а также результаты выборочного исследования ТЕМПЕР ${ }^{16}$.

Доход трудовых мигрантов из Украины за рубежом практически всегда состоит из заработной платы. Учитывая внушительную долю лиц, работающих неофициально, выявление размера зарплаты этой категории населения задача достаточно сложная.

\footnotetext{
16 Данный опрос был составной частью проекта ТЕМПЕР (www.temperproject.eu.), выполнявшимся при поддержке ЕС. Украинским партнером проекта выступал Институт демографии и социальных исследований имени М.В. Птухи НАН Украины. Исследование проходило в декабре 2017-мае 2018 гг. среди украинцев из западных областей, работавших в Италии и Польше в 1996-2017гг. и вернувшихся на родину, а также среди лиц без миграционного опыта. В ходе исследования опрошено 739 обратных мигрантов и 509 человек, не выезжавших за рубеж.
} 
Опираться на статистические данные рынка труда страны трудоустройства в этом вопросе будет неуместно, поскольку в миграционной среде распространена практика, при которой труд мигрантов оплачивается ниже, чем у местного населения. Результаты выборочных исследований могут внести важный вклад в копилку данных относительного этого вопроса. В ходе трех раундов Всеукраинского обследования трудовой миграции респондентам задавали вопрос относительно заработной платы в странах трудоустройства. Для многих респондентов этот вопрос являлся черезчур деликатным и они отказывались предоставлять запрашиваемые сведения, видимо, опасаясь их разглашения. Тем не менее, в процесе опроса удалось получить достаточно надежные данные, которые, однако, разумнее использовать в качестве ориентира. В соответствии с полученной информацией, в 2008 г. среднемесячная зарплата украинских трудовых мигрантов за рубежом составляла 817 дол. США, в 2012 - 913 дол. США, а в 2017 г. - уменшилась до 722 дол. США (Рис. 1.), а это почти в три раза выше, чем соответственный показатель на украинском рынке труда.

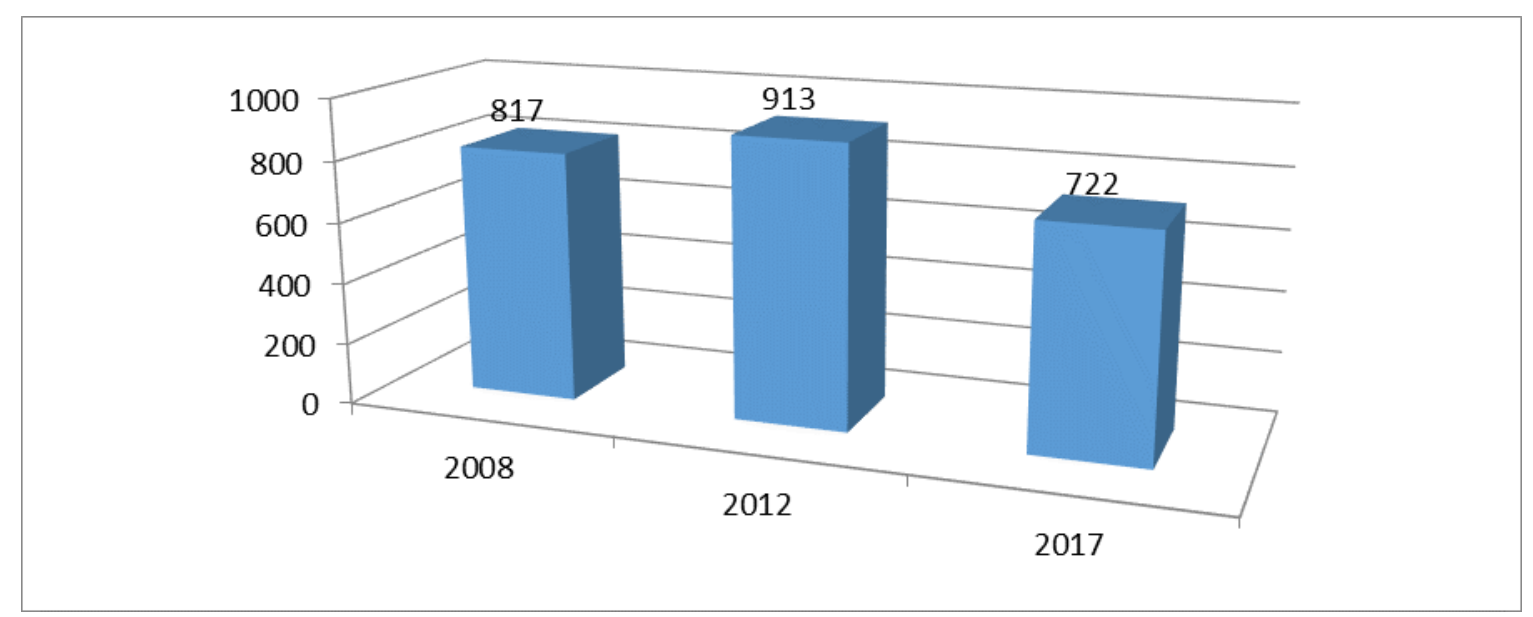

\section{Рисунок 1. Размер среднемесячной зарплаты украинских трудовых мигрантов} за рубежом, дол. США

Источник: Всеукраинское обследование трудовой миграции в 2008, 2012, 2017 гг.

Анализируя использование заработанных за рубежом средств следует учитывать, что часть из них мигранты тратят в странах пребывания, а часть - пересылают домой в виде денежных или натуральних переводов. Такая стратегия поведения оказывает существенное влияние на качество их жизни. Приоритетность потребностей домохозяйства, оставшегося на родине, моральные обязательства относительно членов семьи мигранта, часто приводят к режиму строгой экономии во время пребывания за рубежом. По данным ОТМ, более двух третьих украинских мигрантов, во время пребывания за границей, используют менее четверти заработанных средств, причем между тремя раундами указанного исследования величина этого показателя стабильно возрастала и составляла в 2008 г. - 66,1\%; в 2012 г. $74,6 \%$; в 2017 г. - 79,3\% (Таблица 1.). С помощью использования исключительно количественных данных не представляется возможным оценить - позволяет ли указанное урезание расходов полноценно удовлетворять основные жизненные потребности этой группы населения. Очень важным направлением иследований в этом контексте является изучение влияния миграции на физическое здоровье и психо-эмоциональное состояние человека. 
Таблица 1. Распределение трудових мигрантов из Украины в зависимости от доли заработанных средств, используемых за рубежом, \%

\begin{tabular}{|l|c|c|c|}
\hline & $\mathbf{2 0 0 8}$ г. & $\mathbf{2 0 1 2}$ г. & $\mathbf{2 0 1 7}$ г. \\
\hline До $25 \%$ & $66,1 \%$ & $74,6 \%$ & $79,3 \%$ \\
\hline $26-50 \%$ & $29,9 \%$ & $22,6 \%$ & $18,9 \%$ \\
\hline $51-75 \%$ & $2,9 \%$ & $1,9 \%$ & $1,1 \%$ \\
\hline $76 \%$ и более & $1,1 \%$ & $0,9 \%$ & $0,7 \%$ \\
\hline
\end{tabular}

Источник: Всеукраинское обследование трудовой миграции в 2008, 2012, 2017 гг.

Следует заметить, что количество расходуемых денежных средств - это не единственный показатель, влияющий на жизнедеятельность мигрантов. Важная роль в этом контексте принадлежит условиям труда и доступу до системы социального обеспечения во время пребывания за рубежом. То обстоятельство, что продолжительность робочей недели у трудовых мигрантов в преобладающем количестве случаев значительно превышает законодательные нормативы стран происхождения и трудоустройства, уже давно стало общеизвесным фактом не только в экпертной среде, но и среди общественности. По данным ОТМ, чаще всего продолжительность рабочей недели у трудовых мигрантов из Украины составляла от 41 до 60 часов, близки по значению показатели удельного веса работавших до 40 часов в неделю и от 61 до 80 часов (Таблица 2.).

Таблица 2. Распределение трудових мигрантов из Украины в зависимости от продолжительности рабочей недели за рубежом, \%

\begin{tabular}{|l|c|c|c|}
\hline $\begin{array}{c}\text { Продолжительность } \\
\text { рабочей недели }\end{array}$ & $\mathbf{2 0 0 8}$ г. & $\mathbf{2 0 1 2}$ г. & $\mathbf{2 0 1 7}$ г. \\
\hline До 40 часов & 12,0 & 17,8 & 15,7 \\
\hline $41-60$ часов & 57,1 & 62,6 & 65,5 \\
\hline $61-80$ часов & 16,0 & 14,3 & 16,5 \\
\hline Более 80 часов & 3,6 & 4,6 & 1,8 \\
\hline Не определена & 11,3 & 0,7 & 0,5 \\
\hline
\end{tabular}

Источник: Всеукраинское обследование трудовой миграции в 2008, 2012, 2017 гг.

Многие трудовые мигранты, работая за рубежом, не имеют доступа до системы социального обеспечения, а это, безусловно, влияет на их качество жизни негативным образом. В ходе Всеукраинского обследования трудовой миграции изучению этого вопроса уделялось значительное внимание. В первом раунде исследования (2008 г.) перечень охваченных элементов социального обеспечения был довольно скудным и состоял всего из четырех позиций, в последующих раундах он существенно расширился, что, с одной стороны, предоставляет более подробные данные, но с другой - уменьшает сопоставимость информации.

В соответствии с результатами всех трех раундов ОТМ, приблизительно каждый пятый мигрант не имел возможности пользоваться ни одним элементом системы социального обеспечения в стране трудоустройства. Полученные данные показывают, что доступ остальных респондентов к указанным в анкете благам имел весьма ограниченный характер. Например, по данным двух последних раундов ОТМ, характер и условия занятости четверти опрошенных не подразумевали наличия у них еженедельного выходного; только незначительным по количеству группам респондентов посчастливилось иметь ежегодный оплачиваемый отпуск. Справедливости ради следует отметить, что внушительная группа опрошенных работали за рубежом менее года, следовательно, отсутствие отпуска не может служить основным фактором, характеризующим социальное обеспечение мигрантов в целом. Более подробные данные всех трех раундов ОТМ представлены в Таблище 3. 
В результате растущего интереса исследователей к выявлению нематериальных индикаторов качества жизни населения соответствующие вопросы начали появляться и в программах выборочных исследований миграционных контингентов. При проведении опроса в рамках проекта ТЕМПЕР исследователи остановились на показателе общей удовлетворенности жизнью. Большая часть опрошенных возвратных мигрантов $(52,7 \%)$ отметили частичное удовлетворение жизнью, полностью удовлетворены - 12,4\% почти каждый пятый $(19,1 \%)-$ не смог определиться с ответом на этот вопрос. Удельный вес неудовлетворенных жизнью респондентов относительно невысок: 7,4\% высказали частичную неудовлетворенность, а $3,0 \%$ - полную. Распределение ответов на анализируемый вопрос у мигрантов и лиц, никогда не выезжавших на работу за рубеж, отличается незначительно более высокой долей неудовлетворенных жизнью опрошенных среди последней группы.

Таблица 3. Охват трудовых мигрантов из Украины системой социального обеспечения во время пребывания за рубежом, \%.

\begin{tabular}{|l|c|l|c|c|}
\hline \multicolumn{2}{|c|}{$\mathbf{2 0 0 8}$ г } & & $\mathbf{2 0 1 2}$ г. & $\mathbf{2 0 1 7}$ г. \\
\hline Социальное страхование & $51,5 \%$ & Медицинское страхование & $20,8 \%$ & $21,3 \%$ \\
\hline $\begin{array}{l}\text { Ежегодный } \\
\text { оплачиваемый отпуск }\end{array}$ & $9,4 \%$ & $\begin{array}{l}\text { Ежегодный оплачиваемый } \\
\text { отпуск }\end{array}$ & $18,7 \%$ & $13,2 \%$ \\
\hline Оплата больничного & $3,6 \%$ & Оплата больничного & $11,2 \%$ & $11,3 \%$ \\
\hline $\begin{array}{l}\text { Не имели права ни на } \\
\text { одну льготу }\end{array}$ & $21,1 \%$ & Еженедельный выходной & $74,1 \%$ & $71,7 \%$ \\
\hline Нет ответа & $14,4 \%$ & $\begin{array}{l}\text { Оплата сверхурочной } \\
\text { работы }\end{array}$ & $28,3 \%$ & $30,4 \%$ \\
\hline & & $\begin{array}{l}\text { Социальное страхование } \\
\text { ое имели права ни на } \\
\text { одну льготу }\end{array}$ & $24,7 \%$ & $22,2 \%$ \\
\hline & & Нет ответа & $3,0 \%$ & $2,1 \%$ \\
\hline
\end{tabular}

Источник: Всеукраинское обследование трудовой миграции в 2008, 2012, 2017 гг.

Показатель общей удовлетворенности жизни может усиливаться за счет внедрения вопросов по определению уровня довольства отдельными аспектами жизнедеятельности. Для возвратных мигрантов ключевую роль в этом отношении играет удовлетворенность решением относительно возврата на родину после трудоустройства за рубежом. Почти треть опрошенных (31,3\%) высказали абсолютную удовлетворенность возвратом; 41,9\% отметили вариант «скорее удовлетворен», практически каждый шестой $(16,8 \%)$ высказал нейтральную позицию; скорее и полностью неудовлетворенных оказалось 8,0\% и 2,0\% соответственно. Следует отметить, что достаточно благоприятные данные, выявленные в двух последних показателях, не обязательно указывают на объективную реальность относительно качества жизни. Их следует рассматривать одновременно с объективными показателями, а также учитывать динамику изменений. Психологи свидетельствуют о том, что при ответе на подобные вопросы у человека может срабатывать механизм избегания негативных самоидентификаций, в результате чего благоприятные оценки часто могут оказаться завышенными.

Таким образом, научные исследования в области оценивания качества жизни включают в себя внушительный перечень показателей. На сегодняшний день ни одной экспертной группе не удалось разработать универсальный метод, пригодный для использования во всех без исключения контекстах. Учитывая тот очевидный факт, что качество жизни отдельных групп населения может существенно отличаться от общего показателя, возрастает актуальность исследования вопросов благосостояния для отдельных категорий. Качество жизни мигрантов вызывает научный интерес не только вследствие обширности этой группы, но и ввиду потенциальной возможности существенного изменения 
этого аспекта в результате их активной позиции, направленной на улучшение своего благосостояния. Учитывая ограниченный объем этой работы, а также скудность исходных эмпирических данных, в этой статье удалось коснуться лишь отдельных элементов анализируемой тематики. Огромное сожаление вызывает неспособность проанализировать вопросы, касающиеся здоровья мигрантов, поскольку этот аспект является одним из важнейших в процессе изучения качества жизни. На данном этапе представляется возможным лишь делать гипотетические предположения о том, что неблагоприятные условия труда за рубежом влияют на здоровье мигрантов негативно, однако научная справедливость требует эмпирического подтверждения, дающего возможность не только определить вектор изменений, но и их специфику. Для получения всеобъемлющей картины относительно качества жизни миграционных групп необходимо рассматривать эти вопросы в различных временных локализациях: до выезда за рубеж, на разных этапах пребывания, после возврата на родину (если таковой имеет место), а также учитывать ремиграционный потенциал. Решение каждого из упомянутых заданий может осуществиться только при условии значительного улучшения качества исходных данных, что в свою очередь требует мобилизации финансовых и человеческих ресурсов.

\section{Библиография}

1. Звіт щодо методології, організації проведення та результатів модульного вибіркового обстеження 3 питань трудової міграції в Україні / Міжнародна організація праці. Група технічної підтримки з питань гідної праці та Бюро МОП для країн Центральної та Східної Європи. Будапешт МОП, 2013, 96 с.

2. Зовнішня трудова міграція населення (за результатами модульного вибіркового обстеження). Статистичний бюлетень. К.: Державна служба статистики, 2017, 36 с.

3. Зовнішня трудова міграція населення України. К.: УЦСР, Держкомстат України, 2009, $120 \mathrm{c}$.

4. Final report of the expert group on quality of life indicators. https://ec.europa.eu/eurostat/documents/7870049/7960327/KS-FT-17-004-EN-N.pdf/f29171dbe1a9-4af6-9e96-730e7e11e02f.

5. Happy Planet Index. Official web-site [Электронный pecypc]: http://happyplanetindex.org/. 6. Hartgen M., Klasen S. Well-being of migrant children and migrant youth. https://www.econstor.eu/bitstream/10419/57328/1/608775002.pdf.

7. Hendriks M. Does Migration Increase Happiness? It Depends. https://www.migrationpolicy.org/article/does-migration-increase-happiness-it-depends.

8. McGillivray M., and Clarke M. Human well-being: Concepts and measures. Understanding human well-being. Tokio, New York, Paris. United Nations University Press, p. 3 (p. 3-16). https://pdfs.semanticscholar.org/d5a0/c51829eeedd2aeebcb62879eeaa0f0b4508c.pdf.

9. OECD (2017). How's life? 2017: Measuring well-being, OECD Publishing, Paris. https://read.oecd-ilibrary.org/economics/how-s-life-2017_how_life-2017-en\#page1.

10. The Economist Intelligence Unit's Quality-of-Life Index. https://www.economist.com/media/pdf/QUALITY_OF_LIFE.pdf.

11. United Nations development program. Human development reports. http://hdr.undp.org/en/2018-update. 